\title{
Nasal glial heterotopia in a newborn infant
}

\author{
Catarina Vilarinho, MD, Filipa Ventura, MD, Ana Paula Vieira, MD, Maria João Bastos, MD, \\ Margarida Teixeira, MD, and Celeste Brito, MD
}

From the Departments of Dermatology,

Plastic Surgery, and Pathology, São

Marcos Hospital, Braga, Portugal

\author{
Correspondence \\ Catarina Vilarinho, MD \\ Dermatology Department \\ Hospital Sao Marcos \\ Largo Carlos Amarante \\ Apartado 2242 \\ 4701-965 Braga, Portugal \\ E-mail: catvilarinho@gmail.com
}

A newborn female infant presented at birth with a congenital, $33 \times 25 \times 25-\mathrm{mm}$ mass located on the nasal bridge and protruding along the left nasopalpebral region (Fig. I). The lesion had never bled and there were no problems associated with feeding or breathing. Physical examination revealed a round, solid, nonpulsating, painless tumor covered by erythematous skin with superficial telangiectasias. This mass showed no growth or change in size during crying or jugular vein compression (Furstenberg sign). There were no signs of visual or airway obstruction. The remainder of the physical examination was unremarkable.

Magnetic resonance imaging (MRI) was requested, and sagittal MRI reconstruction images showed that the lesion did not exhibit intracranial extension (Fig. 2).

Based on the clinical appearance of the lesion and lack of intracranial extension, a presumptive diagnosis of lymphangioma of the nasal bridge was established. Serial ophthalmologic examinations were recommended to assess any visual impairment.

During the following months, neither rapid growth nor regression of the lesion was observed, which raised the first clinical suspicion of a misdiagnosis. The infant was referred to the Department of Plastic Surgery, and surgical excision was performed at the age of 18 months (Fig. 3) to prevent further secondary distortion of the nasal bridge and visual developmental sequelae.

Pathologic evaluation of the excised mass showed skin overlying glial tissue positive for glial fibrillary acid protein (GFAP) and enlarged neurons positive for synaptophysin (Fig. 4), consistent with neuroglial heterotopia.

At the age of 2.5 years, the child is doing well with no evidence of local recurrence (Fig. 5 ).

\section{Discussion}

Nasal glial heterotopia and nasal glioma are both correct terms ${ }^{1}$ for the designation of nonhereditary, benign, congenital malformations embryologically related to encephaloceles. ${ }^{2}$ Nasal gliomas are rare lesions occurring once in 20,00040,000 live births, with a total of 250 cases reported in the literature since the first description by Reid in $1852 .{ }^{3}$ Usually, they present at birth or in early childhood ${ }^{2,4-6}$ as a mass in or about the nose, and three types of clinical presentation have been recognized: extranasal $(60 \%)$, intranasal $(30 \%)$, or both (1०\%)..$^{7-9}$ Clinically, external nasal gliomas present as masses that do not transilluminate, are not affected by crying or straining, and do not distend with jugular venous compression (Furstenberg sign). ${ }^{2}$ Hypertelorism may be present. ${ }^{2,4,10}$

The differential diagnosis of a congenital nasal midline mass is wide and should include neurogenic tumors, ectodermal tumors, mesodermal tumors, and teratomas. ${ }^{2}$ As stated above, nasal gliomas represent encephaloceles which have lost their intracranial connection; however, a fibrous stalk is found in I $5-20 \%$ of cases as a relict of this connection. ${ }^{8}$ In this respect, it is important to recognize the potential for a central nervous system or subarachnoid space connection, and to search carefully for evidence of such a connection during diagnostic procedures and before initiating treatment. ${ }^{2-4,7-9, \mathrm{II}}$ Therefore, the evaluation of a congenital midline mass must always include either a computed tomography (CT) or magnetic resonance imaging (MRI) scan to rule out intracranial extension. MRI offers superior soft-tissue contrast, aiding in the planning of the surgical approach, with the additional advantage of saving the child from being exposed 


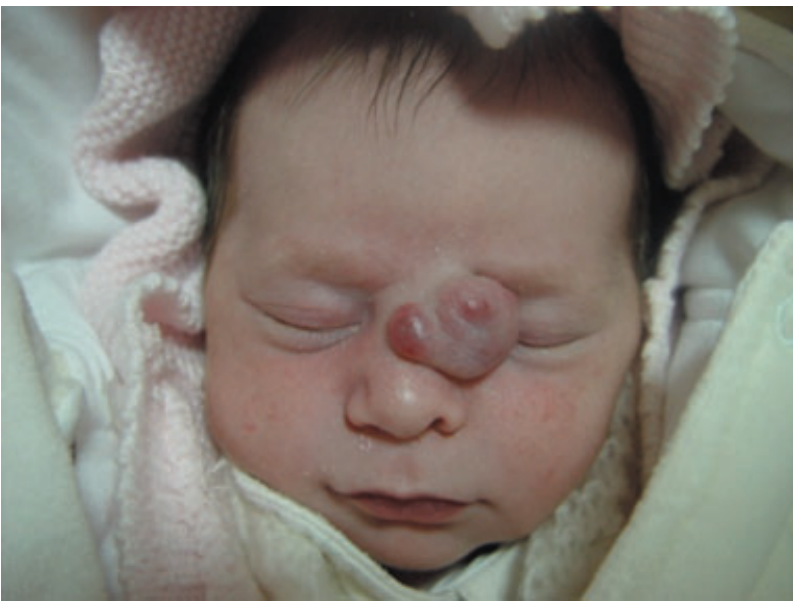

Figure 1 Prominent nasal mass present at birth

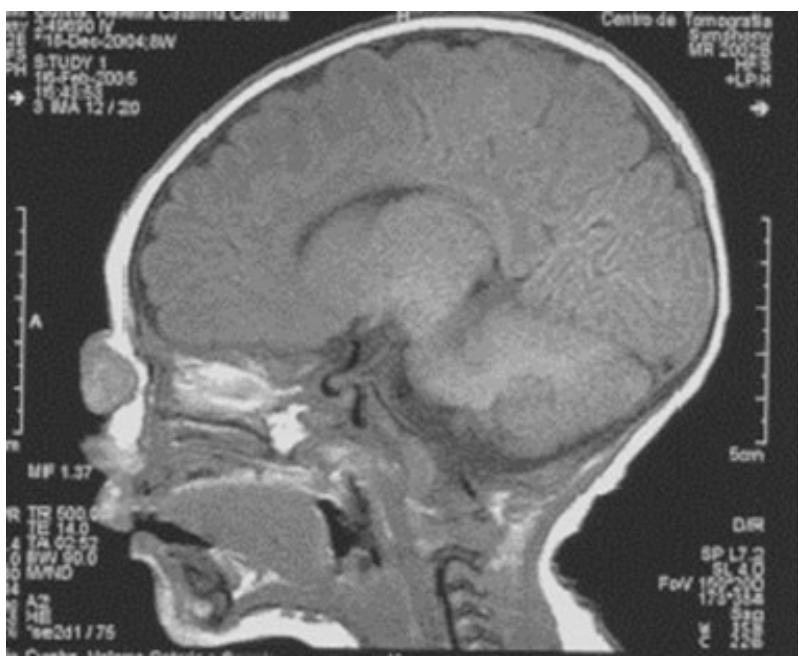

Figure 2 Magnetic resonance imaging demonstrating the extracranial nature of the mass

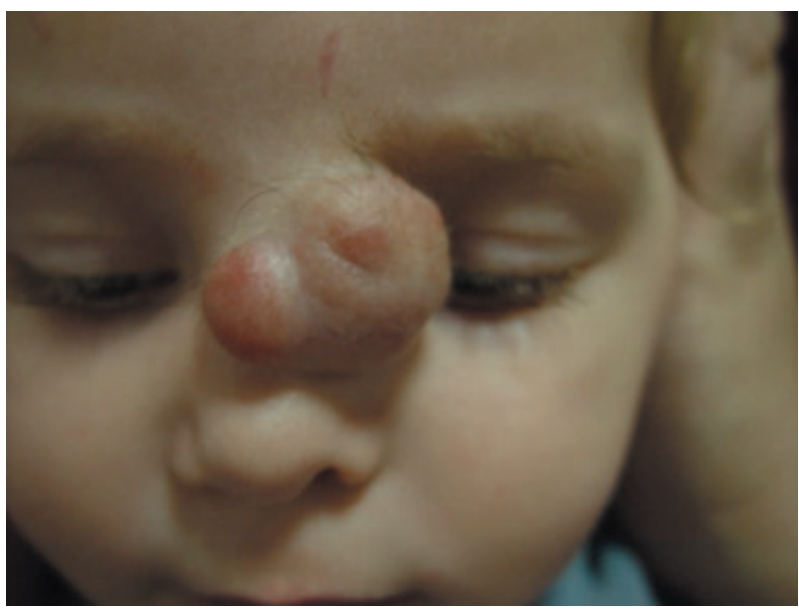

Figure 3 Preoperative view of the lesion at the age of 18 months

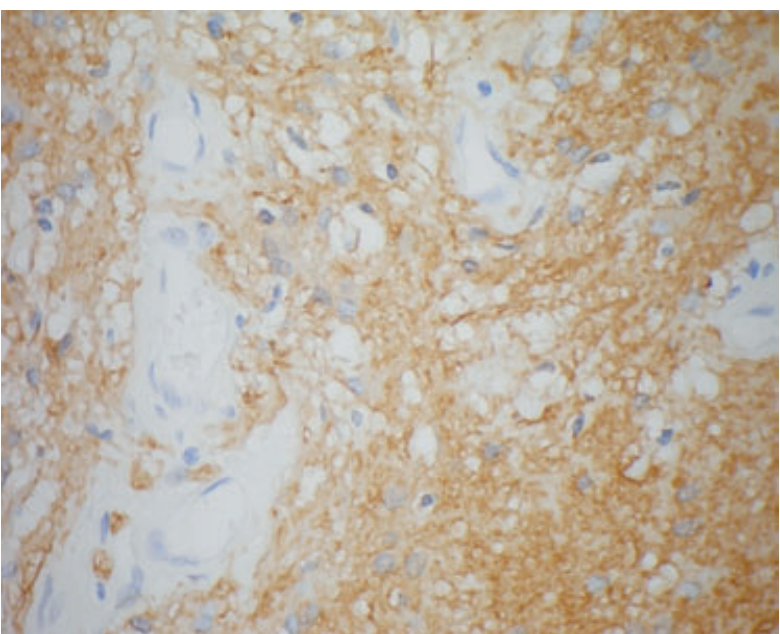

Figure 4 Glial fibrillary acid protein (GFAP) immunoreaction $(\times 400)$

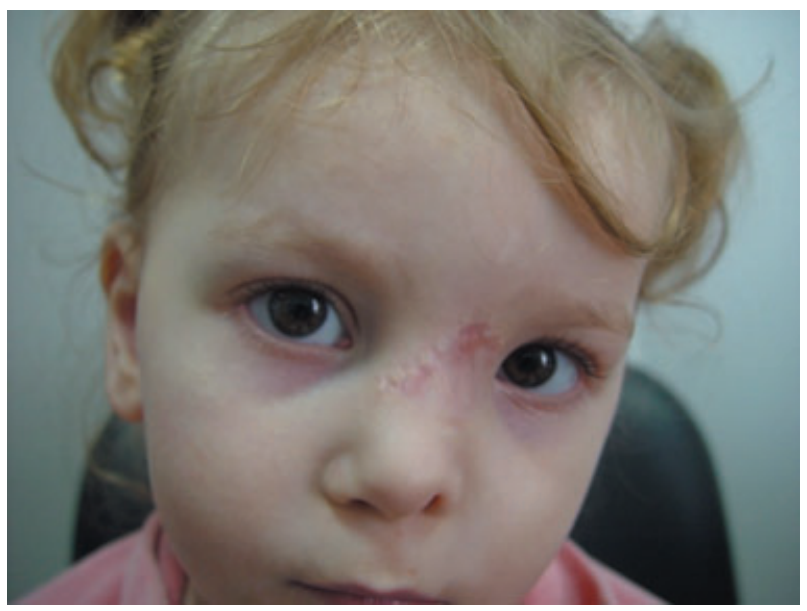

Figure 5 At 2.5 years of age, without any evidence of local recurrence

to ionizing radiation. ${ }^{2,3}$ Incisional or aspiration biopsies are not recommended as they carry the risk of neurologic complications, including meningitis or damage to functional brain tissue. The principal differential diagnoses are vascular tumors, mainly (lympho-) hemangiomas, which represent the most common vascular tumors in infancy. ${ }^{8}$ Therefore, as in our patient, it is not unusual to misdiagnose these entities. $^{8, \mathrm{I}_{2} \mathrm{I} 33}$ Ultrasound is useful for determining whether the mass is cystic or solid, and Doppler flow studies can provide further information regarding the arterial flow patterns. Unlike hemangiomas, which show high arterial Doppler flow velocity during the end-diastolic phase, nasal gliomas demonstrate low arterial flow velocity during the end-diastolic phase. ${ }^{2}$

The treatment of nasal glial heterotopia is surgical, and complete resection is curative. Careful excision is necessary 
because recurrences have been found to occur in $4-10 \%$ of patients, most probably as a result of incomplete primary excision. $^{2}$

Definitive diagnosis is established by pathologic evaluation of the lesion. The histology of nasal glial heterotopia may be difficult to identify with hematoxylin and eosin stain alone. Special stains and immunohistochemistry, such as glial fibrillary acid protein (GFAP) immunostain, which enhances the glial tissue within the background fibrosis, and positive synaptophysin, which confirms the presence of neuronal cells, are thus of great utility when making the diagnosis. ${ }^{4}$

In summary, the greatest difficulty in yielding a diagnosis of nasal glial heterotopia is not considering this condition. The potential for an intracranial connection must always be kept in mind when dealing with a congenital midline mass. MRI imaging should be requested and preoperative biopsies avoided. Doppler flow studies can be performed to differentiate noninvasively between nasal gliomas and (lympho-) hemangiomas. Ultimately, complete surgical excision provides a definitive diagnosis and curative treatment.

\section{References}

I Nicolás-Cerdá M, Sanchez Fernandez de Sevilla C, Lopez-Ginés C, et al. Nasal glioma or nasal glial heterotopia? Clin Neuropathol 2002; 2I: 66-7I.

2 Dasgupta N, Bentz M. Nasal gliomas: identification and differentiation from hemangiomas. J Craniofac Surg 2003; I4: $736-738$.
3 Rouev P, Dimov P, Shomov G. A case of nasal glioma in a new-born infant. Int J Pediatr Otorhinolaryngol 200I; 58 : 9I-94.

4 Penner CR, Thompson LDR. Nasal glial heterotopia: a clinicopathologic and immunophenotypic analysis of Io cases with a review of the literature. Ann Diagn Pathol 2003; 7: 354-359.

5 Chang K, Leu Y. Nasal glioma: a case report. Ear Nose Throat J 200I; 8O: 4IO-4II.

6 Penner CR, Thompson LDR. Nasal glial heterotopia. Ear Nose Throat J 2004; 83: 92-93.

7 Dini M, Lo Russo G, Colafranceschi M. So-called nasal glioma: case report with immunohistochemical study. Tumori I998; 84: 398-402.

8 Hoeger P, Schaefer H, Ussmueller J, et al. Nasal glioma presenting as capillary haemangioma. Eur J Pediatr 200I; I60: $84-87$.

9 Paller AS, Pensler JM, Tomita T. Nasal midline masses in infants and children. Arch Dermatol I99I; I27: $362-366$.

Io Turgut M. Glial heterotopias of the nose. Childs Nerv Syst I997; I3: 569.

I I Hughes GB, Shapiro G, Hunt W, et al. The management of the congenital midline mass - a review. Otolaryngol, Head Neck Surg I980; 2: 222-233.

I 2 Levine MR, Kellis A, Lash R. Nasal glioma masquerading as a capillary hemangioma. Ophthalmol Plast Reconstr Surg 1993; 9: I32-I34.

I3 Oddone M, Granata C, Dalmonte P, et al. Nasal glioma in an infant. Pediatr Radiol 2002; 23: I04-I05. 